\title{
MOVIMENTOS SOCIAIS RURAIS E FEMINISMOS: percursos e diálogos na construção do feminismo camponês e popular
}

\author{
Iolanda Araújo Ferreira dos Santos* \\ Janaina Betto * *
}

\begin{abstract}
Este artigo apresenta uma reflexão sobre alternativas políticas que mulheres camponesas vêm construindo em sua atuação em movimentos sociais rurais no Brasil (no Movimento de Mulheres Camponesas e no Movimento dos Trabalhadores Rurais Sem Terra). A partir de revisão bibliográfica, análise documental, entrevistas e participação em eventos, buscamos compreender como as dirigentes camponesas, organizadas politicamente, têm procurado alternativas às desigualdades nas relações de gênero no meio rural e pensado a construção do feminismo tendo em vista suas vivências no campo. Entendemos que suas reivindicações levam a uma política própria, criada por mulheres para toda a sociedade, da qual emerge esse feminismo ainda em elaboração, mas que já afirma a busca por novas relações de gênero, de produção e com a natureza, a partir das práticas cotidianas do "modo de vida" das mulheres camponesas. Mesmo diante do avanço do neoconservadorismo no Brasil, essas mulheres estão construindo o feminismo camponês e popular como movimento de autonomia e esperança.
\end{abstract}

Palavras-chave: Feminismo Camponês. Gênero. Campesinato. Mulheres Rurais. Esperança.

\section{INTRODUÇÃO}

Uma parte dos estudos sobre o campesinato no Brasil contribuiu para construir uma perspectiva da família rural como um todo unido. ${ }^{1}$ Outra parte se dedicou a pensar sobre processos de masculinização do rural, nos quais se verificou na família a primeira instância de controle social. ${ }^{2}$ É notável a influência dessas perspectivas sobre certo modo de falar da mulher, partindo da invisibilidade como recorte analítico. Além disso, o avanço dos estu-

\footnotetext{
* Universidade Federal de Santa Maria. Departamento de Educação Agrícola e Extensão Rural (Deaer).

Avenida Roraima, 1000, Camobi. Cep: 97105-900. Santa Maria - Rio Grande do Sul - Brasil. iolanda_uast@yahoo. com.br

https://orcid.org/0000-0001-7595-7884

* * Universidade Federal de Santa Maria. Programa de Pós-Graduação em Extensão Rural.

Avenida Roraima, 1000, Camobi. Cep: 97105-900. Santa Maria - Rio Grande do Sul, Brasil. janaina.btt@hotmail.com https://orcid.org/0000-0002-8068-5075

${ }^{1}$ Segundo Paulilo (2016b), a sociologia rural historicamente privilegiou a ideia de família rural como um todo unido. São estudos que receberam forte influência chayanoviana.

${ }^{2}$ A perspectiva da masculinização do rural foi bastante enfatizada no final da década de 1990 e na década de 2000, como nos estudos de Camarano e Abramovay (1999) e Stropasolas (2006).
}

dos de gênero e do campesinato geraram novas interpretações sobre a condição social das mulheres no meio rural (Brumer, 2004; Carneiro, 1994; 2001; Paulilo, 2016a) ${ }^{3}$ e sobre diversos aspectos de sua organização em movimentos sociais rurais (Aguiar, 2016; Bordalo, 2011; Deere, 2004; Paulilo, 2004). Além dos estudos, as próprias mulheres camponesas organizadas politicamente passaram a influenciar a emergência de novos recortes analíticos, pois suas agendas políticas, sobretudo nas duas últimas décadas, também vêm afetando a agenda de pesquisa, em virtude da "demanda" por compreender as variações em seus processos de organização política e, mais recentemente, em vista da construção do feminismo camponês e popular (Betto; Piccin, 2017; Paulilo, 2016b; Santos; Zimmermann, 2019).

É perceptível a maior abrangência de estudos feministas com interesses voltados à situação ${ }^{3}$ Maria Ignez Paulilo é pioneira nesses estudos. Os prin-
cipais foram compilados no livro Mulheres rurais: quatro
décadas de diálogo (Paulilo, 2016a). Os estudos de Maria
José Carneiro (1994; 2001) versam sobre a condição social
de gênero no meio rural e sua influência nos processos de
herança. O artigo de Anita Brumer (2004) trata da inserção
das mulheres na agricultura familiar e da seletividade de
gênero nos processos migratórios. 
das mulheres urbanas, ${ }^{4}$ principalmente devido à grande importância que as teorias marxistas tiveram nos primórdios do feminismo em nosso país (Betto; Piccin, 2017; Paulilo, 2016b; Santos; Picolotto, 2019). De modo menos expressivo, há discussões feministas associadas a questões consideradas como específicas do mundo rural, como a produção de alimentos saudáveis e a soberania alimentar, ou a relação humana com a natureza e/ou com a terra. Nesse âmbito, destacamos algumas correntes feministas, como o ecofeminismo (Mies; Shiva, 1993) e o ambientalismo feminista (Agarwal, 2004), e, mais recentemente, aquelas que apostam em reflexões que aproximam feminismo e ecologia e diversificam as questões das mulheres no mundo (Paredes, 2013; Stengers, 2017; Tola, 2016). ${ }^{5}$ Notamos também a emergência e consolidação de feminismos que propõem olhares sobre os impactos do racismo e da colonialidade na vida das mulheres, e que convidam a refletir acerca da diversidade que constitui as experiências e os pontos de vista das mulheres, conforme as opressões diversas que as atravessam e a realidade que vivenciam, como o feminismo decolonial (Lugones, 2014) e o feminismo negro norte-americano e brasileiro (Akotirene, 2019; Collins, 2018).

Neste artigo buscamos compreender como as mulheres camponesas organizadas politicamente têm procurado alternativas às desigualdades nas relações de gênero no meio rural e como têm pensado a construção do feminisনี mo a partir de suas vivências no campo. Para . tanto, damos centralidade às trajetórias organizativas das dirigentes no Movimento de Mulhe¿ res Camponesas (MMC) e no Movimento dos $\rightarrow$ Trabalhadores Rurais Sem Terra (MST), a fim

$\overbrace{}^{4}$ A designação feminismo urbano é utilizada como um ๓. marcador de experiência/ponto de vista, uma vez que não

$>$ existe um movimento ou vertente que se intitula como tal.

oิ No entanto, consideramos importante demarcar que, ao

T. longo da história do feminismo, o termo foi construído e

\pm pensado primordialmente desde as experiências e pontos

क de vista de mulheres em contextos urbanos. Essa categoria

- também é utilizada pelas entrevistadas para diferenciar o

feminismo que constroem.

${ }^{5}$ Trata-se, principalmente, de estudos influenciados por cosmovivências indígenas latinas, pela antropologia simé-

trica e pelo perspectivismo ameríndio, isto é, de maneira geral, pelo avanço de teorias pós-estruturalistas. de esmiuçar articulações políticas, estratégias discursivas e o desabrochar do feminismo camponês e popular, o que permite refletir sobre seu caráter de movimento de autonomia e de esperança (Dinerstein, 2015) para as mulheres camponesas, principalmente em contraposição ao avanço do neoconservadorismo no Brasil e em diálogo com perspectivas feministas diversas.

Salientamos a opção pelo uso dos termos neoconservadorismo e nova direita conservadora ao longo do artigo. Ambos se referem à emergência da extrema direita no mundo, que parte de discursos de vítimas do establishment intelectual das universidades e da grande mídia, instituindo um cenário de disputa entre regimes de verdade, ${ }^{6}$ para além da disputa entre regimes econômicos, e abarcando a disputa de noções e valores sociais mais amplos, entre os quais o papel e a posição das mulheres na sociedade (Pinheiro-Machado, 2019).

Destacamos que, no que tange às informações relacionadas ao Movimento de Mulheres Camponesas, recorremos a um estudo realizado Betto (2016) durante seu mestrado, no qual é discutida a trajetória do MMC em Santa Catarina e sua influência na consolidação nacional do movimento, bem como a trajetória de vida das dirigentes jovens do MMC. Desse modo, as reflexões sobre o MMC apresentadas neste artigo tomam por base a pesquisa de campo realizada pela autora em 2015 e 2016, que teve como ponto de partida a participação no evento "Direitos das mulheres e avanço do conservadorismo no Brasil" (2015), a análise de documentos e cartilhas do acervo histórico do MMC-SC, ${ }^{7}$ bem como entrevistas abertas ${ }^{8}$

\footnotetext{
${ }^{6}$ Regimes de verdade no sentido foucaultiano, ou seja, disputas em torno de grandes padrões de verdade da sociedade (grandes debates), como as ideias de direitos humanos e de civilização.

7 Pesquisa de campo de cunho qualitativo, com recorte temporal desde a década de 1980, período de surgimento do MMC-SC, até 2016. Os documentos analisados são as relatorias de todas as assembleias realizadas pelo MMC-SC durante essa época, bem como as cartilhas produzidas pelo MMC-SC no mesmo período.

${ }^{8}$ Foram realizadas cinco entrevistas abertas com jovens dirigentes do MMC. Além disso, houve uma entrevista com uma dirigente da geração que acompanhou o processo de
} criação do MMC-SC na década de 1980. 
com jovens dirigentes do MMC. Por sua vez, em relação às informações apresentadas sobre o MST, dialogamos com a tese de doutorado de Santos (2019), cuja pesquisa de campo foi elaborada em 2017 e 2018 a partir da participação no evento "Jornada de Lutas das Mulheres Sem Terra no 8 de Março", da análise de documentos $^{9}$ do acervo do MST-RS e de entrevistas ${ }^{10}$ com dirigentes do MST. Também foram incluídas informações advindas da participação da autora no curso on-line "Questão agrária e patriarcalismo" (2020).

\section{MOVIMENTO DOS TRABALHADO- RES RURAIS SEM TERRA: trajetória das mulheres em um movimento misto}

As origens do Movimento de Trabalhadores Rurais Sem Terra remontam ao final da década de 1970 e início da década de 1980, a partir de conflitos fundiários que reivindicavam o acesso à terra. Formalmente, foi fundado em 1984 e, desde sua origem, como movimento de luta por reforma agrária, é composto por homens e mulheres, caracterizando-se como um movimento "misto". Entretanto, mesmo que teoricamente nunca tenha existido restrição à participação feminina em qualquer instância do MST, historicamente se percebe a predominância de homens em cargos de liderança, seja ela política, administrativa ou produtiva. Ainda nos primórdios da trajetória do MST foram as mulheres que, mobilizadas, tomaram a iniciativa de discutir os problemas relacionados à sua integração e aos seus direitos no movimento. Conforme retratado por Santos e Picolotto (2019), desde o Primeiro Congresso Nacional do MST, em 1985, as mulheres reivindicam seu direito à participação política, ocupando a mesa diretora e conquistando a

9 Pesquisa de campo de cunho qualitativo, com recorte temporal entre o período de surgimento do MST na década de 1980 e 2018. Parte dos documentos analisados foi obtida na Hemeroteca Luta Pela Terra (digital) e parte por consulta aos arquivos da biblioteca do MST-RS.

${ }^{10}$ Foram realizadas seis entrevistas abertas com mulheres dirigentes do MST. cota de 30\% de participação nas instâncias de direção do MST e em todas as atividades promovidas pelo movimento.

Importa frisar que algumas mulheres presentes no Primeiro Congresso Nacional do MST que iniciaram o questionamento sobre a participação feminina no movimento tinham uma experiência anterior de militância, seja nas Comunidades Eclesiais de Base, seja nas oposições sindicais e/ou organizações específicas de mulheres rurais. Autoras que resgatam um pouco da trajetória organizativa das mulheres do campo (Aguiar, 2016; Deere, 2004; Gonçalves, 2009) destacam a importância de sua organização no sindicalismo, do qual emergem os movimentos autônomos de mulheres do campo. Além disso, destacam como isso influenciou seu despertar por espaço e voz nos movimentos mistos. Portanto, desde o estabelecimento da cota de $30 \%$ de participação feminina até hoje, a presença das mulheres no MST foi conquistada e garantida pela articulação e organização próprias, e, na maior parte do tempo, mantiveram algum tipo de estruturação no interior do movimento. Para isso, durante as atividades políticas do MST (como nos encontros e congressos), elas se reuniam em espaços paralelos, muitas vezes em horários destinados ao descanso ou a atividades culturais, para discutir e construir estratégias de intervenção nos espaços formais que eram comandados pelos homens.

O MST sempre manteve um discurso segundo o qual participação das mulheres não era proibida, mas elas deveriam conquistar seu espaço. Essa ideia de "conquista de espaço" leva a crer que esse espaço não é/era delas, ou, pelo menos, que não foi pensado para possibilitar a integração feminina. Nesse sentido, Paulilo (2004) chama a atenção para o fato de que nos movimentos que enfatizam as questões de classe, o modelo de participação política privilegia os homens, cobrando que as mulheres assumam o comportamento considerado "masculino". Além do mais, esse discurso pode ser entendido como uma estratégia 
de manutenção do poder político dos homens, uma vez que aponta para a ausência das mulheres como motivo para estarem à frente do movimento. Por exemplo, Santos e Picolotto (2019) descrevem a trajetória organizativa feminina no MST em fases caracterizadas por sucessivas transformações no planejamento interno, sendo cada fase marcada pela discussão sobre como as suas pautas deveriam ser tratadas, ou seja, em alguns momentos abordadas como importantes e, em outros, como distração do foco central do movimento. Após contínua mobilização e organização das mulheres, o MST, com o objetivo de estender o debate sobre a construção de relações de gênero mais igualitárias para o conjunto do movimento, e não apenas restrita a grupos ou coletivos de mulheres, aprovou, em 2000, a criação do Setor Nacional de Gênero, a partir do entendimento de que em um movimento misto o avanço só é real se for para todos, e que, por isso, o debate não poderia estar restrito aos coletivos de mulheres, mas integrar organicamente o movimento (MST, 2017).

A incorporação da discussão de gênero no MST, concretizada com a instituição desse setor específico, é resultado da organização e mobilização das mulheres e demonstra um avanço do movimento no sentido de tornar esse debate institucionalizado. É interessante destacar que o principal objetivo do setor era garantir a participação efetiva das mulheres nos espaços de decisão, impondo também essa $\overrightarrow{\tilde{N}}$ responsabilidade (de garantir a inclusão feminina) para os homens que estavam nessas instâncias, o que superava o discurso de que o es¿ paço deveria ser conquistado pelas mulheres.

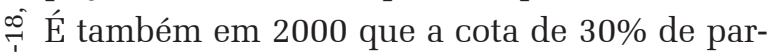
$\dot{2}$ ticipação feminina nos congressos e instâncias ले do movimento é rediscutida, instituindo-se a paridade de gênero, o que implicava ter 50\% de mulheres em todos os processos de decisão do MST. Assim, percebe-se que garantir a participação feminina foi uma das primeiras pautas resultantes da auto-organização das mulheres dentro do MST. Além disso, a constituição do Setor de Gênero também contribuiu para a inserção e fortalecimento da perspectiva feminista no MST, por meio da formação das mulheres em cursos com temas sobre "feminismo e marxismo", promovidos pelo setor a partir dos anos 2000.

A estruturação do setor foi se modificando ao longo do tempo e, atualmente, possui três frentes de trabalho: (a) a questão da auto-organização interna e formação das mulheres; (b) o debate de gênero com os homens; e (c) a questão LGBTQI+s. A composição do Setor de Gênero com base nessas três frentes representa o esforço de construir novas relações no movimento e nas famílias que o compõem, por meio do trabalho com os homens e da importância dada ao processo de formação e organização interna das mulheres, mediante a frente de trabalho formada por elas. O que há de novo é a frente de trabalho LGBTQI+s, que emerge a partir da segunda metade da década de 2010 e se consolida em 2015, momento em que se começa a debater, no MST, a diversidade afetivo-sexual, considerando sua importância para a construção de relações de gênero mais justas e igualitárias.

No geral, o Setor de Gênero, constituído e dirigido por mulheres, tem gerado muitos avanços para o MST, seja por meio da formação e inserção de novos quadros políticos femininos, seja pela organização de atos públicos que dão visibilidade ao movimento, ou ainda pela promoção de debates importantes presentes na sociedade. Além disso, é preciso considerar que o interesse do MST em construir uma política de equidade de gênero se baseia, de acordo com Debiasi (2017), para além do eixo de ação interno, no resultado da auto-organização das mulheres, e é também motivado por questões externas, fruto da vinculação do MST com movimentos sociais internacionais, como a Via Campesina, e dos intercâmbios e diálogos mais recentes com movimentos feministas. É importante considerar que, desde o final da década de 1980, as mulheres do MST estão articuladas com as demais organizações de mulheres rurais, promovendo encontros para 
debater a participação e seu papel na política, a exemplo do I Encontro Nacional da Mulher Trabalhadora Rural, organizado pelas mulheres do MST e da CUT, que ocorreu em 1986 e pautou sua participação em movimentos sociais, sindicatos e partidos políticos. Além disso, um importante marco na organização política das mulheres rurais é a criação da Articulação Nacional da Mulher Trabalhadora Rural (ANMTR), consolidada no Encontro Nacional de Mulheres Trabalhadoras Rurais, ocorrido em 1995. Outro ponto a ser destacado é a aproximação do MST com a Via Campesina, no final da década de 1990. Conforme apontado por Santos e Picolotto (2019), o MST se aproxima da Via Campesina ao mesmo tempo que se afasta da Central Única de Trabalhadores (CUT), sugerindo que esses fatores influenciaram o debate interno das mulheres do MST, inclusive no que concerne à sua identidade, já que antes eram mobilizadas pela categoria de "mulher trabalhadora rural", passando paulatinamente a se mobilizar mais como "mulher camponesa”.

Ao longo dos anos, as mulheres organizadas no MST conseguiram avançar em pautas importantes, dentro e fora do movimento. Internamente, a mobilização feminina resultou em conquistas como a participação em postos de direção (mediante a paridade de gênero), a construção da ciranda infantil (que possibilita que mães participem dos espaços políticos) e a formação do Setor Nacional de Gênero como institucionalização do debate de gênero no MST. Como conquistas resultantes da luta das mulheres rurais, incluindo as mulheres do MST, no cenário externo podemos citar o direito à Previdência Social e à licença maternidade, e o direito de constar como "titular" dos lotes, entre outras políticas públicas para mulheres rurais. Além dessas que podem ser caracterizadas como "pautas de interesse das mulheres", a participação e mobilização sempre foram fundamentais no movimento, pois elas sempre se fizeram presentes na linha de frente das ações.

\section{FEMINISMO CAMPONÊS E POPU- LAR PELAS MÃOS DAS MULHE- RES DO MST}

É a partir da constituição do Setor de Gênero e, mais fortemente, após a inserção do MST na Via Campesina, que as mulheres sem-terra - já identificadas como "mulheres camponesas" - começam a fortalecer no MST a perspectiva feminista. Nessa aproximação entre "campesinato" e "feminismo", duas coisas devem ser destacadas: primeiro, a vinculação do movimento à Via Campesina, que implica uma ressignificação do que é ser camponês; e, segundo, a identificação das mulheres camponesas com o feminismo marxista, que se esforça em vincular questões de classe e gênero, estabelecidas a partir de espaços internos de formação. Para as dirigentes do MST entrevistadas, é imprescindível que se faça a relação entre classe e gênero. E é essa luta que elas travam internamente desde os primórdios do MST: fazer que o movimento reconheça essa relação como indissociável. De acordo com relatos das dirigentes entrevistadas, a luta feminista deve estar nos movimentos de luta de classes, assim como os movimentos feministas precisam incorporar o viés classista. Para essas mulheres, é primordial a relação entre feminismo e socialismo, pois é insuficiente investir no debate da libertação feminina se não se avança também na questão de classe social.

Da mesma forma, entendem que a questão da classe por si só não resolve os seus problemas, de onde decorre a importância da organização e mobilização dentro do movimento. Uma das dirigentes entrevistadas ${ }^{11}$ aponta que elas anseiam por caminhar "lado a lado" com os homens na perspectiva da luta de classes (mais especificamente, a luta pela terra), porém reconhece que existe uma caminhada mais árdua que precisam percorrer para avançar na questão de gênero. De acordo com

${ }^{11}$ Entrevista com a dirigente Clara (nome fictício) do MST. Mais detalhes em Santos (2019). 
outra dirigente entrevistada, ${ }^{12}$ a luta contra a opressão de gênero precisa andar "de mãos dadas" com a luta pela terra, e deve ser travada também em conjunto com os homens. Para ela, mesmo que dialoguem com movimentos autônomos, é importante manter o debate de gênero no MST com os homens, pois é assim que se estrutura a sociedade. Entretanto, as dirigentes entrevistadas concordam que a articulação com outros movimentos de mulheres, como a Marcha Mundial de Mulheres e o Movimento de Mulheres Camponesas, foi fundamental para que se avançasse em pautas feministas no interior do movimento e para a formação e o empoderamento das mulheres do MST.

Por se tratar de um movimento misto, as mulheres do MST reforçam a importância de os homens discutirem as relações de gênero. Nesse sentido, surge, a partir do Setor de Gênero, o "Coletivo de Homens do Setor de Gênero”, organizado para repensar as próprias práticas e participar da construção de novas relações de gênero no contexto do movimento. Na cartilha mais recente do Setor (MST, 2017) podemos encontrar um texto elaborado pelo Coletivo de Homens que trata da importância de também combaterem o patriarcado como parte da luta por transformação social, pois, se as opressões de gênero forem mantidas, a transformação almejada da sociedade não será completa. No $18^{\circ}$ Encontro Estadual do MST do Rio Grande do Sul, ocorrido em dezembro 今ิ de 2017, foi realizada a $1^{\text {a }}$ Assembleia Estadual . de Homens do MST, espaço organizado pelo Setor de Gênero no qual os homens se reuniram para discutir a relação entre patriarcado e capitalismo e o desafio na construção de novas ¿. relações de gênero para a constituição de uma ले nova sociedade. Essa assembleia demonstrou $\vec{i}$ iniciativas concretas por parte dos homens inseridos na discussão de gênero e demarcou uma ruptura com a lógica de que gênero é um problema das mulheres.

A tentativa de articulação histórica

${ }^{12}$ Entrevista com a dirigente Dandara (nome fictício) do MST. Mais detalhes em Santos (2019). entre classe e gênero também está relacionada com a necessidade de as mulheres rurais "provarem" para os militantes homens que a questão de gênero é importante para o projeto de transformação da sociedade, e que isso não implica o enfraquecimento da luta de classes. Uma das lideranças do MST entrevistada afirmou que na luta do movimento o que se busca é o socialismo. Então, um dos principais gritos de ordem das mulheres é: "sem feminismo não há socialismo". E, assim, o esforço das dirigentes vem no sentido de demarcar a importância de construir novas relações de gênero no percurso da luta de classes, pois entender a luta feminista como importante instrumento para alcançar a mudança que se almeja na sociedade é fundamental para que mais mulheres camponesas afirmem a identidade feminista. No entanto, assumir-se como mulher camponesa e feminista implica também ressignificar esses conceitos. Nesse ínterim, o MST assume como vertente feminista o chamado feminismo marxista ou, como se referem algumas entrevistadas, o feminismo revolucionário. Desde a constituição do Setor de Gênero esse coletivo tem ofertado cursos de formação sobre feminismo e marxismo, e elaborado cartilhas e textos que falam sobre esse tema e abordam a importância do feminismo na luta pelo socialismo, mobilizando-as a participarem de tais iniciativas.

As mulheres dirigentes do MST entrevistadas também indicam que foi por meio da Via Campesina, e em especial do Movimento de Mulheres Camponesas, que o termo feminismo camponês e popular começou a ser forjado. O entendimento que reforça a necessidade de um feminismo camponês é de que as pautas de luta das mulheres camponesas têm particularidades e especificidades que não são enxergadas no feminismo construído por mulheres urbanas. O feminismo camponês e popular vem sendo trabalhado entre as mulheres camponesas como algo em construção, com o objetivo de que elas próprias agreguem sentidos a esse termo. Uma das dirigentes entre- 
vistadas $^{13}$ ressaltou que o feminismo camponês não pode se restringir às mulheres, e que é necessário que englobe toda a comunidade, inclusive os homens.

É importante retomar que, ao se afirmarem como "camponesas", essas mulheres, além de demarcar uma identidade de classe, fazem referência ao conceito de campesinato ressignificado, com forte sentido político, relacionado à luta contra o agronegócio, em defesa da soberania alimentar e da produção agroecológica. Tais pautas ganharam relevância inclusive nas lutas do 8 de março, e nunca é demais relembrar a importância da ação mobilizada dessa data, em 2006, quando cerca de 1.800 mulheres da Via Campesina ocuparam o viveiro horto florestal da Aracruz Celulose, no município de Barra do Ribeiro, Rio Grande do Sul. Nesse contexto, a ação foi estratégica no sentido de chamar a atenção da imprensa nacional e internacional e do público presente no evento da Organização das Nações Unidas para a Alimentação e Agricultura (FAO), que acontecia no mesmo dia, em Porto Alegre. O sucesso da ação esteve, sobretudo, na sua capacidade de consolidar a imagem das mulheres camponesas na luta contra o avanço do agronegócio e das transnacionais, e em defesa da biodiversidade e da vida.

A posição institucional do MST quanto ao feminismo é indicada na última cartilha publicada pelo Setor de Gênero, na qual nota-se que o movimento de fato assume o feminismo camponês e popular, apresentando-o como um feminismo "vinculado à classe trabalhadora" e que surge "no campo, nos embates com o agronegócio e a mineração, demarcando a realidade dessa luta” (MST, 2017, p. 20). Percebe-se que o feminismo camponês e popular não trata "apenas" do que se considera "coisa de mulher”, mas ganha força entre as mulheres do MST por aproximar a luta de classes da luta feminista e da defesa do campesinato. Compreendemos que o conceito de campesinato no

${ }^{13}$ Entrevista com a dirigente Rosa (nome fictício) do MST. Mais detalhes em Santos (2019).
Brasil passou por uma ressignificação, ${ }^{14}$ especialmente como estratégia para o fortalecimento dos movimentos sociais do campo que defendem essa categoria política. Nesse processo de ressignificação, o "diferencial" da mulher camponesa seria a resistência ao agronegócio e a busca por um modelo de agricultura agroecológico, que respeita a relação dos seres humanos entre si e com a natureza. A partir do conceito de campesinato ressignificado emerge um feminismo que reconhece as particularidades e necessidades das mulheres do campo, um feminismo que não abandona as questões de classe e que atenta para as relações das mulheres com a natureza, a terra e a distribuição de renda, colocando-as como protagonistas da construção de um novo modelo de agricultura e sociedade possível (Santos, 2019).

Além desses aspectos bastante comentados sobre a criação do Setor de Gênero e a construção do feminismo camponês e popular, nos chamou a atenção o ponto de vista da dirigente Rosa Negra, mulher camponesa negra. Durante uma aula do curso on-line "Questão agrária e patriarcalismo", realizado em 2020, Rosa Negra destacou a necessidade de olhar para a imbricação entre gênero, classe e raça. Com um discurso contendo elementos não evidenciados nas narrativas das dirigentes entrevistadas, ela enfatizou que a articulação entre classe e gênero não contempla as mulheres negras, e fez menções a feministas negras para argumentar sobre a importância de as mulheres camponesas estudarem e defenderem a perspectiva negra da interseccionalidade como um dos alicerces do feminismo camponês e popular. A interseccionalidade visa instrumentalizar teórico-metodologicamente a inseparabilidade estrutural do racismo, capitalismo e patriarcado (Akotirene, 2019). Para a dirigente, "latifúndio, patriarcado e racismo" são os três pilares que estruturam o capitalismo e devem ser enfrentados em conjunto. Por isso ela si-

${ }^{14}$ Essa discussão ocorre desde Martins (1995), ao refletir sobre a entrada do campesinato no debate político nacional, e tem sido bastante debatida por autores como Wanderley (2003) e, internamente, nos movimentos sociais rurais. 
naliza que esse diálogo ainda é escasso, mas essencial para a construção do feminismo camponês e popular.

\section{MOVIMENTO DE MULHERES CAM- PONESAS DO BRASIL: trajetória das mulheres em um movimento autônomo}

A retomada do processo histórico de constituição do Movimento de Mulheres Camponesas (MMC-Brasil) é feita com base em informações referentes à construção do movimento em Santa Catarina, a fim de compreendermos sua influência na consolidação do movimento na esfera nacional e em discussões referentes ao seu feminismo camponês e popular. O MMC-SC, inicialmente Movimento de Mulheres Agricultoras de Santa Catarina (MMA-SC), foi fundado oficialmente em 1983, e seu surgimento está relacionado às mobilizações políticas do novo sindicalismo, promovidas por setores da Igreja Católica vinculados à Teologia da Libertação. A partir dessa organização inicial, tornou-se perceptível a falta de acesso aos direitos sociais como consequência do não reconhecimento de seu trabalho e de sua profissão como agricultoras. Nos anos seguintes, organizaram diversas caravanas a Brasília em busca de direitos como o reconhecimento da profissão de "trabalhadoras rurais/ নี agricultoras", a documentação das mulheres - e a licença-maternidade (MMC, 1987). Adentrar no espaço dos sindicatos permitiu a essas mulheres perceber que suas dificuldades não क se relacionavam simplesmente à falta de uma $\dot{2}$ identidade profissional, mas que eram discriif minadas pelo fato de serem mulheres.

\section{Desde a primeira assembleia do MMA-} -SC (MMC, 1983),$^{15}$ notou-se que a condição da mulher e suas experiências - no âmbito da família, da sociedade e da política - dava o

$151^{\mathrm{a}}$ Assembleia Estadual do MMA-SC (1983). No entanto, essas percepções são recorrentes nas relatorias de outras assembleias e fizeram parte das discussões que balizaram o seminário acompanhado em 2015. tom das discussões realizadas. Nesse sentido, remonta-se à percepção de uma das entrevistadas, ${ }^{16}$ fundadora do MMA-SC, de que o movimento surgiu da falta de espaço para a mulher na política, sobretudo nos sindicatos. Desse modo, o MMA se tornou um lugar propício para as discussões de gênero e troca de experiências entre as mulheres e proporcionou a elas compreender a dimensão de poder que dificultava sua atuação política. O estudo realizado por Paulilo (2004) demonstra que nesse espaço elas dialogavam livremente acerca das desigualdades que lhes eram mais cotidianas, como as que se reproduzem dentro do grupo familiar ou do sindicato, o que também permitiu construir uma compreensão diferenciada da "luta", com a qual conflitos de classe e de gênero estão intimamente relacionados. Com isso, já no final da década de 1980 as mulheres organizadas no MMA passaram a sentir a necessidade de ter mais liberdade para definir e expandir suas interpretações sobre suas lutas, o que passou pelo interesse sobre temas até então pouco conhecidos, como o próprio "feminismo", no início da década de 1990 (MMC, 1990).

No mesmo período elas buscaram ampliar a articulação com outros movimentos de mulheres e movimentos mistos, processo perceptível ainda em 1986, quando ocorreu o $1^{\circ}$ Encontro Nacional de Mulheres Trabalhadoras Rurais. Em 1995 foi realizado um encontro nacional de organizações de mulheres para efetivar a criação da Articulação ANMTR. A instituição da ANMTR gerou maior articulação entre mulheres trabalhadoras rurais em nível nacional, bem como a consolidação dos eixos centrais de suas lutas (gênero e classe) como indissociáveis, o que demonstra certa aproximação com articulações realizadas por dirigentes do MST no mesmo período.

No que se refere à sua articulação internacional, o MMA-SC, por intermédio da ANMTR, participou da $1^{\text {a }}$ Conferência Latino-Americana de Mulheres do Campo, realizada du-

${ }^{16}$ Entrevista com a dirigente 1, dirigente estadual do MMC-SC, que participa do movimento desde a sua origem. 
rante a $2^{\text {a }}$ Conferência da Coordenação Latino-Americana de Organizações (Cloc), em 1997, momento em que o movimento de mulheres redesenha suas atuações com base no enfrentamento ao avanço da política neoliberal em âmbito mundial. Nesse sentido, o debate sobre modelo de agricultura ganha mais centralidade no final da década de 1990, juntamente à aproximação com a Via Campesina.

Dentro da ANMTR, o MMA-SC teve papel central no debate acerca da contribuição das mulheres do campo para a construção de um novo modelo de agricultura. Consequentemente, retoma-se o fato de que a busca por construir um modelo de agricultura a partir da realidade de mulheres do MMA-SC antecedeu o processo de unificação das diversas organizações autônomas de mulheres do campo, e contou com diversas discussões em municípios e regiões de atuação do MMA-SC. Todos esses esforços se tornaram fatores constitutivos do processo que levou à consolidação do MMC-Brasil.

O MMC-Brasil foi criado oficialmente em 2004, momento em que a articulação de mulheres rurais na esfera nacional (ANMTR) deixa de existir. ${ }^{17}$ No mesmo ano ocorreu a $4^{\mathrm{a}}$ Conferência da Via Campesina no Brasil, organização que o MMC passa a compor (MMC, 2004). Diante dessa nacionalização, as antigas categorias "trabalhadora rural" e "agricultora" foram substituídas pela designação "camponesa”, o que representa uma das mudanças mais significativas dessa reconfiguração. Para os movimentos da Via Campesina, a identidade "camponesa" também carrega conotação política, perspectiva em que as mulheres do campo são sujeitas ativas tanto na agricultura como politicamente, pois elas cooperam para construir um modelo de agricultura que estimula o enfrentamento ao projeto neoliberal.

${ }^{17}$ Cabe esclarecer que o fim da ANMTR e a nacionalização do MMC também representaram a dissidência entre diferentes organizacões regionais/estaduais de "trabalhadoras rurais" no Brasil, ocasionando a divisão entre organizações que passaram a usar a designação "mulheres camponesas" e as organizações que se mantiveram identificadas com a designação "trabalhadoras rurais", sobretudo organizações localizadas na região Nordeste e que não compuseram o MMC-Brasil.
Ao mesmo tempo, cabe considerar que, para as militantes do MMC, a mudança da definição de "trabalhadoras rurais/agricultoras" para "camponesas" também se deu com base em estudos sobre a categoria campesinato (MMC, 2002). Diante disso, a expansão dos significados alia-se à construção de um projeto de agricultura camponesa. No entanto, para elas, o processo de ressignificação não se dá apenas no sentido produtivo, mas principalmente no âmbito das relações envolvidas: relações sociais entre homens e mulheres e destes com a natureza (MMC, 2010, 2014). Na $11^{\mathrm{a}}$ Assembleia Estadual do MMC-SC, realizada em 2010 (MMC, 2010), as dirigentes presentes deliberam oficialmente que o movimento tinha um caráter feminista, momento em que as discussões passaram a ter como base o tema "identidade camponesa e feminista". Obviamente não se trata de "datar" o feminismo do MMC, visto que o movimento tem toda a sua trajetória marcada por práticas que podemos considerar como feministas, mas sim de concluir que foi após o MMC assumir o caráter feminista de suas práticas políticas que se criou a necessidade de mais definições acerca do que representava para elas o feminismo.

\section{FEMINISMO CAMPONÊS E POPU- LAR PELAS MÃOS DAS MULHE- RES DO MMC}

A partir da $12^{\mathrm{a}}$ Assembleia Estadual do MMC-SC (MMC, 2014), iniciou-se um processo de delineamento sobre o feminismo do movimento, tendo como um dos principais pontos de discussão a diferenciação entre este e o feminismo urbano. Essa distinção pode ser compreendida levando em conta o fato de os feminismos urbanos não reconhecerem em suas formulações as peculiaridades do modo de vida camponês, nem o formato de trabalho familiar (Betto; Piccin, 2017). Nesse sentido, também vimos em Paulilo (2016b) o reconhecimento de que pautas feministas que buscam 
soluções coletivas, como em relação ao cuidado com a casa e com filhos(as), por vezes são muito distantes das condições de vida no campo. Desse modo, delimitarmos que esse feminismo é diferente do feminismo urbano significa também demarcar que a forma como as opressões de gênero são vivenciadas se altera conforme o modo de vida em questão e o espaço social em que as relações são construídas.

Diante de um modelo de agricultura que prioriza a vida e a participação das mulheres camponesas (MMC, 2007, 2010, 2014), uma das dirigentes entrevistadas ${ }^{18}$ considera que o feminismo é camponês porque procura valorizar aspectos desse modo de vida, como os conhecimentos tradicionais e a sua importância para a segurança alimentar e a preservação da biodiversidade, nas quais a maneira de produzir evoca outra relação com a natureza, de forma contrária à produção de commodities do agronegócio. Conforme outra entrevistada, ${ }^{19}$ a valorização do trabalho da mulher camponesa passa por sua relação com a terra, com as sementes crioulas, pela produção de alimentos e pelas diversas nuances da capacidade de "produção de vida" que elas carregam.

Assim, o modo de vida camponês que buscam valorizar contém aspectos de uma identidade social alicerçada no cotidiano da mulher rural, o que se torna também uma identidade política, procurando significar o termo "camponês" com base no projeto de agricultura camponesa proposto pelo MMC. Por isso, há ন̃ também nessa percepção o reconhecimento de ำ dução do agronegócio é considerado parte da luta feminista camponesa em defesa da vida, sondo assim um feminismo que propõe alter¿. nativas para a agricultura baseadas nas experiÆ̛̀ ências de produção e de cuidado que vêm das práticas cotidianas de mulheres camponesas. Como afirmam as camponesas, é preciso valorizar as atividades comumente femininas por-

${ }^{18}$ Entrevista com jovem dirigente 4, dirigente nacional do MMC. Mais detalhes em Betto (2016).

${ }^{19}$ Entrevista com jovem dirigente 2, dirigente nacional do MMC. Mais detalhes em Betto (2016). que elas foram desvalorizadas por serem consideradas "das mulheres" (MMC, 2010, 2014).

No entanto, devemos nos ater principalmente à percepção de que essa ressignificação não se restringe apenas a aspectos do âmbito produtivo, uma vez que as proposições das mulheres camponesas denunciam perspectivas que destoam do "modo de vida camponês", trazendo para o centro do debate as relações sociais de gênero no campesinato, já que o modo de vida camponês que o MMC defende é livre de relações desiguais e de violências para com as mulheres camponesas. Há também discussões sobre sexualidade e o direito ao aborto. Em Betto e Piccin (2017) já observávamos a valorização da capacidade da mulher camponesa em gerar vida, em suas múltiplas formas, de maneira simultânea à valorização do direito ao aborto, demonstrando aspectos de um feminismo construído com base em experiências de vida cotidiana e em debates feministas atuais. De acordo com Paulilo (2016b), essa simultaneidade seria contraditória apenas se considerássemos "mais atuais" como sinônimo de "mais evoluídos", postura que colocaria certo tom evolucionista entre diferentes feminismos, o que buscamos evitar.

Ademais, essa formulação feminista tem o importante papel de conferir às organizações e aos movimentos sociais rurais a relevância da discussão sobre relações de gênero para os processos de transformação social, papel que vem sendo desempenhado desde a origem do MMC. O feminismo camponês e popular cobra das demais organizações do campo o entendimento de que falar de gênero não é falar de mulheres, mas sim falar de relações constitutivas da sociedade em que vivemos.

Além do mais, retomando afirmações do MMC como "a luta contra o capital tem que ser feminista" e "a luta feminista só é emancipatória se for contra o capital”, ${ }^{20}$ voltamos à própria

${ }^{20}$ Essa afirmação foi resgatada do seminário de 2015. No entanto, é importante acrescentar o quanto ela costuma ser citada e enfatizada nos espaços de discussão sobre o feminismo camponês e popular, bem como em diversas cartilhas elaboradas pelo MMC. 
história de constituição do movimento. Se, por um lado, seu feminismo tem o compromisso de demonstrar a importância da luta feminista para a transformação da sociedade, de outro, entoa a narrativa que afirma necessária uma aproximação entre luta feminista e luta de classes. Fruto da trajetória do MMC, o feminismo se constitui a partir de uma relação indissociável entre classe e gênero (Betto; Piccin, 2017), e é nessa aproximação que as militantes localizam o caráter popular do feminismo camponês. Diante de tal característica, o feminismo camponês e popular vem sendo apontado como se andasse na contramão de certa tendência, por parte do feminismo urbano, de afastamento da luta de classes (Paulilo, 2016b). ${ }^{21}$

De todo modo, ainda que justificável pela trajetória da mobilização das mulheres camponesas, é importante considerar que esse caráter classista (ou popular) do feminismo camponês é também decorrente dos estudos dessas mulheres camponesas que, ao longo da trajetória do MMC, realizaram formações com influência teórica e política advindas do feminismo marxista. Esse reconhecimento nos convida a evitar o erro de pensar que ações e formulações de mulheres camponesas estariam totalmente à parte das discussões teóricas feministas. Autoras como Silvia Federici (2017) têm sido referência para essas mulheres, endossando a perspectiva de que o capitalismo necessitou de intervenção sobre corpos e conhecimentos femininos para se constituir, e de que o patriarcado é um sistema de dominação que sustenta o capitalismo.

É importante considerar que, em virtude dessa aproximação, elas não estão entoando visões clássicas marxistas de que o fim da divisão de classes resolveria as questões de gênero. Exemplo disso foi demonstrado no seminário realizado em 2015. Sendo um evento organizado pelo MMC, foi interessante perceber que a presença de outros movimentos e organizações

${ }^{21}$ Ainda que de fundamental importância, essa discussão precisa ser aprofundada, sobretudo diante da emergência de feminismos que tratam da centralidade da questão de raça, por exemplo, sem se afastar da questão de classe. em uma das mesas de debate tencionou uma leitura que considera gênero como uma "nuvem de fumaça que esconde outras questões por trás". ${ }^{22}$ As feministas camponesas presentes no evento não concordaram. Para elas, o avanço da força política conservadora depende da derrota das conquistas históricas das mulheres. Isso demonstra que elas já haviam notado sinais de que nos anos seguintes as "questões de gênero" teriam a pertinência política que vimos ter, pois, afinal, como dizem reiteradamente em seus seminários, suas assembleias e cartilhas, "o patriarcado sustenta o capitalismo".

O feminismo camponês e popular, como elas afirmam, é uma construção política coletiva que expressa o acúmulo de mulheres camponesas organizadas e articuladas com outros movimentos vinculados à Cloc/Via Campesina. Trata-se, na perspectiva do MMC, da expressão própria que as mulheres camponesas dão à luta pela transformação social. Nesse sentido, o feminismo camponês e popular não é simplesmente uma luta para mulheres, mas uma luta de mulheres em defesa da vida, afinal, para elas, o avanço do capitalismo não leva ao desenvolvimento das forças produtivas, apenas à devastação da vida nas suas mais variadas formas. Recordemos das palavras de Silvia Federici (2017, p. 27), autora citada pelas dirigentes: "Marx nunca poderia ter suposto que o capitalismo preparava o caminho para a libertação humana se tivesse olhado sua história do ponto de vista das mulheres".

\section{O NEOCONSERVADORISMO E AS FEMINISTAS CAMPONESAS: DIANTE DO ÓDIO SEMEAR A ES- PERANÇA}

Todos os anos o 8 de Março (Dia Internacional da Mulher) é símbolo de luta e resistência das mulheres e de movimentos feministas em todo o mundo. Nessa data as mulheres organizadas no MST realizam alguns atos políti${ }^{22}$ Fala registrada durante o evento. 
cos para chamar a atenção da sociedade para a luta das mulheres camponesas. Nos últimos anos esses atos compõem as "Jornadas de Luta das Mulheres", que compreendem espaços de formação interna e um dia de luta nas ruas (8 de março). Em 2018 tivemos a oportunidade de acompanhar a Jornada de Luta das Mulheres do MST-RS, que teve como lema "Mulheres camponesas em defesa da democracia, pela soberania nacional e nenhum direito a menos". Durante a jornada ocorreram diversos espaços de formação, mas todos direcionavam ao mesmo ponto: o cenário político nacional que se desenhava com Michel Temer na presidência e a candidatura de Jair Bolsonaro, e a forma como o avanço do conservadorismo afetava a reforma agrária, a reprodução social dos assentamentos e a vida das mulheres.

A maior discussão se deu pela tentativa de responder à questão: como as mulheres poderiam se organizar contra esse governo? Para tanto, promoveram um espaço de formação com a participação da ex-presidenta Dilma Rousseff (Partido dos Trabalhadores - PT). Em seu discurso para as mulheres do MST, Dilma Rousseff destacou o caráter "machista e misógino" do golpe que sofreu em agosto de 2016, e comentou sobre a importância do MST para as lutas sociais do Brasil. A ex-presidenta ainda ressaltou que, durante os meses de luta contra o golpe, a resistência foi feminina, pois eram as mulheres que estavam na linha de frente dos atos em defesa নิ da democracia. Outro importante espaço de for- mação promovido nessa jornada contou com a presença da então deputada estadual Manuela ¿ D’Ávila (Partido Comunista do Brasil - PCdoB), $\rightarrow$ que destacou a relevância do feminismo para o $\dot{2}$ fortalecimento das mulheres do campo na luta ङீ por seus direitos. A deputada também comentou sobre os desdobramentos do golpe e o avanço do conservadorismo no país, apontando para a emergência de um movimento antidemocrático que tenderia a calar a voz dos movimentos sociais, especialmente das mulheres, pois a cada vez que elas avançavam se dirigiam contra a política conservadora que as exclui.
Em período mais recente, já em 2020, no contexto da pandemia de Covid-19, as mulheres do MST têm organizado atividades mensais, iniciadas em abril e realizadas todo dia 8 de cada mês, com o lema "Mulheres Sem Terra contra o vírus e as violências". Nessas atividades on-line elas debatem sobre como se proteger do vírus e das violências de gênero que têm se acirrado durante o isolamento social. Além da violência no âmbito privado, elas enfatizam a violência do atual governo conservador que ameaça os direitos das mulheres, conquistados com muito esforço. Nesse sentido, as discussões têm ocorrido com base no grito de ordem "Fora Bolsonaro", e as mulheres têm se apresentado como resistência nesse contexto, citando como principal ferramenta de luta na atualidade o feminismo camponês popular.

No seminário "Direitos das mulheres e avanço do conservadorismo no Brasil”, realizado em 2015, as dirigentes do MMC caracterizaram o avanço do conservadorismo como uma reação, em parte, à emergência das minorias nas últimas décadas (nas quais se incluem as mulheres camponesas). Para elas, se as mulheres avançam, as forças conservadoras regridem, e vice-versa. Além disso, afirmaram que o conservadorismo vem de setores que não aceitam a autonomia das mulheres.

As discussões durante esse seminário remontam à visão de dirigentes do MMA-SC, que já na década de 1990 apontavam como um dos principais inimigos das mulheres a "ideologia conservadora da família (tradicional)" (MMC, 1990). É por essa razão que as dirigentes afirmaram que nem tudo no discurso conservador é novidade, pois entendem que "o poder sempre esteve nas mãos de homens armados, proprietários e líderes religiosos” ${ }^{23}$. A diferença é que hoje esses setores conservadores formaram alianças e estão cada vez mais presentes dentro do Estado. Para elas, um retrocesso nos direitos das mulheres não é um problema apenas delas, pois também indica uma dinâmica de avanço do capital.

${ }^{23}$ Falado durante o evento "Direitos das mulheres e avanço do conservadorismo no Brasil” (2015). 
Para Biroli, Machado e Vaggione (2020), a reação à agenda de igualdade de gênero é global, mas tem contornos próprios no contexto latino-americano, no qual o processo é marcado pela atualização do conservadorismo religioso, que fortalece alianças políticas com outros setores em nome de uma hegemonia "moral", em que a defesa da família implica legitimação de violências e restrição de direitos. Essas alianças têm se fortalecido na atuação parlamentar e no desmonte de políticas públicas importantes para mulheres e minorias.

Notemos que a ofensiva neoconservadora atual tem como um dos pilares o ataque ao que chamam de "ideologia de gênero", fazendo uso de narrativas centradas na defesa da família "tradicional", do familismo e de uma espécie de defesa da vida, aspectos que servem à criminalização de lutas históricas das mulheres. Messenberg (2019) identificou três principais campos semânticos de formação de opinião da nova direita conservadora, a saber: o antipetismo, o conservadorismo moral e os princípios neoliberais. No campo do conservadorismo moral, aponta como uma das principais ideias de força o conceito de família tradicional como oposição ao casamento entre pessoas do mesmo sexo, ao aborto e à "ideologia de gênero".

Nesse âmbito, recorremos à percepção de Pinheiro-Machado (2019), segundo a qual o neoconservadorismo se constrói com base em uma disputa de regimes de verdade, ancorada na construção de narrativas como essas, que envolvem uma posição de vítimas do establishment intelectual das universidades. Além disso, para a autora, o reacionarismo emergente também pode ser entendido, entre muitos outros fatores, como uma reação à explosão do feminismo, do antirracismo e das lutas de grupos LGBTQI+s. Consideramos que essa reação também pode ser caracterizada como reação à conquista de direitos pelos sujeitos vinculados ao meio rural, em que se inserem os avanços conquistados pelas mulheres camponesas. Por outro lado, Pinheiro-Machado (2019) considera que pouco se fala a respeito dos desdobramentos desses movimentos (feminismo, antirracismo, LGBTQI+s e, aqui, também movimentos os rurais), como o caráter de ruptura da estrutura social que geram, ruptura marcada por uma nova geração de mulheres, por exemplo.

Nesse caudal, o marco histórico do movimento \#EleNão, ${ }^{24}$ de 29 de setembro de 2018, é citado pela autora como um fato político que convida a entender a participação das mulheres na política, na qual mulheres falavam umas com as outras para conquistar o voto da vizinha, da prima, da amiga ou da tia. Para a autora, algo muito profundo acontece no tecido social quando mulheres vão para a rua rejeitar o projeto autoritário, o que em partes passa pela movimentação de mulheres que enfrentam pais, irmãos e maridos para disputar opiniões de mães, avós e parentes que apenas seguiam o que o "homem da casa" definia. Nesse sentido, discussões nas primeiras assembleias do MMA-SC demonstram essa movimentação desde a década de 1980, quando, para a construção de suas reuniões e ações, foram necessários esforços por parte das dirigentes, por meio de visitas e conversas com maridos e familiares para garantir a participação política de outras mulheres.

Lembremos também que militantes do MST e do MMC estiveram nos atos \#EleNão de 2018. As militantes participaram não apenas por uma opção individual, mas também pela orientação e "linha política" dos movimentos na luta contra o avanço do conservadorismo, demonstrando mais uma vez existir nessa luta contra o poder neoconservador o protagonismo das mulheres camponesas dentro dos movimentos sociais rurais que, ao lado das mulheres urbanas, ocuparam as ruas e fizeram uso de adereços como chapéus de palha e chita para demarcar a identidade camponesa: "nos encontramos nas ruas, de onde nunca saí${ }^{24} \mathrm{O}$ \#EleNão foi um movimento de mulheres marcado por sua ocupação nas ruas de todo o Brasil, em 29 de setembro de 2018, contra a candidatura de Jair Bolsonaro, candidato que colecionou declarações que podem ser consideradas de cunho fascista, especialmente contra mulheres, negros, grupos LGBTQI+s? e movimentos sociais em geral. 
mos. Dia 29 é como março que nunca acabou. É luta e ousadia, com lilás, vermelho e chita. Essa é a garra, a beleza e a mística da luta das mulheres" (Mulheres..., 2018).

Essa ideia de um "março que nunca acabou" nos convida a adentrar na trajetória de vida de uma das entrevistadas e pensá-la como parte das inúmeras trajetórias de luta de mulheres camponesas ao longo das últimas décadas. Uma das jovens dirigentes do MMC entrevistada $^{25}$ relatou a insistência da mãe, militante do MMC, em mudar o modelo de agricultura na propriedade familiar, ganhando reforços a partir do momento em que ela também se inseriu no movimento e passou a fazer cobranças à família. Com a militância de mãe e filha elas conseguiram, depois de muita insistência, convencer toda a família a modificar o modelo produtivo. No entanto, o que se destacou em sua fala foram as condições colocadas para aceitar participar de tal processo, que são mudanças nas relações de poder dentro da família: ser incluída na tomada de decisões, que a divisão do trabalho produtivo e reprodutivo fosse feita de forma igualitária e que toda a renda fosse dividida em partes iguais entre os membros da família. A mudança na forma de agricultura foi precedida pela alteração na hierarquia familiar, por décadas inquestionável, em que relações de poder dentro da família rural precisaram ceder lugar a maior horizontalidade. Esse breve exemplo deixa provocações సิ acerca de possíveis novas agendas de pesquiก $\mathrm{sa}^{26}$ sobre impactos da organização política de mulheres no âmbito das famílias rurais. $\stackrel{\infty}{+}$ da de decisões, divisão igualitária do trabalho $\dot{2}$ produtivo e reprodutivo, divisão de renda faÆi miliar é algo sintomático de mudanças que $\vec{i}$ exigiram longo período de construção. Tudo

${ }^{25}$ Entrevista com jovem dirigente 5, dirigente estadual do MMC-SC. Mais detalhes em Betto (2016).

${ }^{26}$ Por exemplo, quanto às filhas de militantes e quanto ao modo como se dão as relações de gênero nas famílias que vieram a constituir na vida adulta, considerando a influência das narrativas de suas mães sobre a forma como elas interpretam questões de gênero, de igualdade e de diferença, ou ainda na relação que possuem com o feminismo. isso aliado a mulheres propondo projeto de agricultura com novas relações sociais e com a natureza, situação que o neoconservadorismo não tolera facilmente. Isso nos lembra que o conservadorismo não é novidade na vida das mulheres, pois leis e direitos fundamentais nunca funcionaram completamente para alguns segmentos da sociedade. É diante de um momento histórico de construção de novos discursos acerca de como mulheres camponesas podem viver que certos regimes de verdade são reforçados e reelaborados.

Nessa esteira, o feminismo camponês e popular vem se consolidando como um discurso em potencial nesse cenário de disputas. Em consonância com formulações de Bina Agarwal (2004), que estudou gênero e meio ambiente a partir de experiências de agricultoras na Índia, a defesa dos vínculos femininos simbólicos e materiais com seu meio de vida passa longe da defesa de uma "essência" feminina, pois pressupõe gênero, cultura e natureza como constructos sociais e históricos. A relação dessas mulheres com a natureza deve ser entendida, na sua materialidade, como forma específica de interação que se constrói em contextos próprios. Agarwal (2004) defende que é nas vivências cotidianas que se encontram práticas e maneiras de conceber o mundo que têm o potencial de construção de alternativas para toda a sociedade.

O que vemos na construção do feminismo camponês e popular são mulheres camponesas, historicamente responsáveis pela segurança alimentar de suas famílias, que defendem que isso seja parte de um projeto de sociedade. Mulheres que compreendem que violência de gênero implica a necessidade de falar sobre gênero para alcançar uma sociedade igualitária. Mulheres que, a partir de experiências de cuidado com a vida, acreditam que a vida deve ser defendida em suas mais variadas formas. A emergência do "tema da vida" está em consonância com o observado por autores que analisam mobilizações contemporâneas latinas (Escobar, 2015) e mobilizações prota- 
gonizadas por mulheres (Stengers, 2017; Tola, 2016). Trata-se da prática de realocar o domínio da vida na agenda política diante de um cenário de avanço de discursos que celebram o ódio, o extermínio e a morte.

Essas considerações se aproximam da Política da autonomia na América Latina, de Ana Cecília Dinerstein (2015), observando o protagonismo das mulheres camponesas mais além, como um movimento de esperança que tem a capacidade de criar alternativas, novos modos de vida e novos mundos todos os dias, mediante a prática de uma utopia concreta que organiza a esperança na luta contra a barbárie. E, como lembra a autora, afirmar uma nova realidade alicerçada na prática tem o efeito real de desnaturalizar e negar a realidade de opressão como a única possível no aqui e agora. Em espaços de formação, as mulheres camponesas reforçam que a mobilização delas não pode ser caracterizada apenas como uma denúncia, devendo ainda ser percebida como um anúncio de que elas estão organizadas para construir outro mundo possível. Como lembra a Pedagogia da esperança, de Paulo Freire (1992), esperança implica a denúncia das injustiças e opressões, mas também a anunciação da capacidade humana de desfatalizar a condição de opressão e de construir esse "inédito viável" por meio da ação articulada de sujeitos.

\section{CONSIDERAÇÕES FINAIS}

Ao longo da história dos movimentos sociais rurais, as camponesas levantaram bandeiras como a luta pela reforma agrária, pelo fim do sistema capitalista e em defesa de um novo modelo de agricultura. Suas lutas também passam pela busca de igualdade em relação aos homens, por direitos historicamente negados a elas, como direitos trabalhistas, bem como o de ter espaço na política por meio da criação de um movimento autônomo ou da conquista por paridade de gênero nas instâncias do movimento misto.
Ao mesmo tempo, suas reivindicações apontam para a busca pela valorização da diferença nas relações de gênero, pautando o reconhecimento da importância de certos saberes e fazeres baseados em vínculos socialmente construídos como femininos, que se remetem a aspectos de seus cotidianos no modo de vida camponês, a partir de um ponto de vista que valoriza, por exemplo, o fato de as mulheres camponesas serem as principais responsáveis pela alimentação de suas famílias, pelo resgate de sementes crioulas e pelo conhecimento de plantas medicinais. Trata-se de reconhecer o valor da relação com a natureza como vínculo feminino, ${ }^{27}$ porque elas não a veem como algo que as essencializa, mas sim como uma construção histórica que confere qualidade positiva, pois saber se relacionar de outra forma com a natureza - que não a exploração e devastação do modelo capitalista - têm grande importância para pensar uma nova sociedade.

Assim, as mulheres camponesas valorizam aquilo que historicamente foi atribuído a elas e que, por ser "do mundo das mulheres", foi desvalorizado, negado, amaldiçoado, odiado. Suas reivindicações levam a uma política própria, feita por mulheres para toda a sociedade, que é o feminismo camponês e popular, ainda em construção, mas que já afirma como centralidade a busca por novas relações de gênero, livres de todas as formas de violência, novas relações de produção e com a natureza, para uma agricultura que valoriza o cuidado com a vida e que tem como alicerce as práticas do cotidiano do "modo de vida" das mulheres camponesas.

Ao olhar para o percurso da luta feminista das camponesas não procuramos encaixar suas demandas nesse ou naquele feminismo. Evidenciamos, sim, características de um feminismo marxista. Todavia, suas construções políticas nos levam além, convidam a pensar em uma luta em defesa da vida, em contraposição à agricultura de morte do agro-

${ }^{27}$ A designação de vínculos femininos vem de estudos de Bina Agarwal, realizados na Índia, e se refere a valores construídos socialmente no dia a dia de mulheres rurais e não ao valor "essencial" ou "natural" de mulheres. 
negócio. Desse modo, de maneira semelhante ao ambientalismo feminista, parece haver uma virtuosa relação entre a busca pela transformação de discursos e práticas acerca das formas de relação entre pessoas (e entre estas e a natureza) e a busca pela transformação dos meios de apropriação de grupos dominantes na sociedade capitalista. Além disso, recentemente, há sinais de espaço para diálogo oportuno com perspectivas que consideram questões raciais em patamar de igualdade com gênero e classe.

Diante de vivências e discursos de feministas camponesas relatados no decorrer deste artigo, entendemos que essas dirigentes vêm construindo criativamente o seu feminismo camponês e popular como um movimento de autonomia e esperança, mesmo diante de um cenário desanimador de avanço de um poder neoconservador, que reafirma a "ideologia de gênero" da misoginia - essa política de ódio contra as mulheres, contra o que elas criam e o que já conquistaram. Olhar a trajetória das mulheres em movimentos sociais rurais nos leva a perceber que desde o início elas lutam contra certo conservadorismo, e que as alternativas que propõem para a vida das mulheres camponesas oferecem benefícios para toda a sociedade, pautando novos regimes discursivos e transformações estruturais. Observamos, ainda, alguns indícios de mudança na vida cotidiana das famílias rurais, especulação que demanda novas pesquisas. Ademais, como as mulheres ¿ี camponesas afirmam em seus espaços, "é preciㅇ. so manter a esperança”, essa ferramenta histórica daquelas para as quais o conservadorismo não se trata exatamente de pura novidade.

Recebido para publicação em 19 de novembro de 2020 Aceito em 23 de abril de 2021

\section{REFERÊNCIAS}

AGARWAL, B. El debate sobre género y medio ambiente: lecciones de la India. In: VÁZQUEZ, V.; VELÁSQUEZ, M. (comp.). Ambientalismo feminista. Ciudad de México: Universidad Autónoma de México, 2004. p. 239-285.

AGUIAR, V. V. P. Mulheres rurais, movimento social e participação: reflexões a partir da Marcha das
Margaridas. Política \& Sociedade, Florianópolis, v. 15 , p. 261-295, 2016.

AKOTIRENE, C. Interseccionalidade. São Paulo: Pólen, 2019.

BETTO, J. Chega de ficar de fora já chegou a hora de participar: trajetória política do MMC/SC e o engajamento militante das dirigentes "jovens camponesas". 2016. Dissertação (Mestrado em Extensão Rural) - Universidade Federal de Santa Maria, Santa Maria, 2016.

BETTO, J.; PICCIN, M. B. Movimento de Mulheres Camponesas (MMC/SC) e o percurso de sua luta feminista. Amerika, Rennes, v. 16, 2017. Disponível em: http:// amerika.revues.org/8202. Acesso em: 2 jun. 2021.

BIROLI, F.; MACHADO, M. D. C.; VAGGIONE, J. M. Gênero, neoconservadorismo e democracia. São Paulo: Boitempo, 2020.

BORDALO, C. A. Os caminhos da política: o sindicalismo rural e os movimentos de mulheres trabalhadoras rurais em Pernambuco. 2011. Dissertação (Mestrado em Ciências) - Universidade Federal Rural do Rio de Janeiro, Rio de Janeiro, 2011.

BRUMER. A. Gênero e agricultura: a situação da mulher na agricultura do Rio Grande do Sul. Estudos Feministas, Florianópolis, v. 12, n. 1, p. 205-227, 2004.

CAMARANO, A. A.; ABRAMOVAY, R. Exxodo rural, envelhecimento e masculinização no Brasil: panorama dos últimos 50 anos. Rio de Janeiro: Ipea, 1999.

CARNEIRO, M. J. Herança e gênero entre agricultores familiares. Estudos Feministas, Florianópolis, v. 9, p. 22$55,2001$.

. Mulheres no campo: notas sobre sua participação política e a condição social do gênero. Estudos, Sociedade e Agricultura, Rio de Janeiro, v. 2, n. 1, p. 11-22, 1994.

COLLINS, P. H. Epistemologia feminista negra. In: BERNARDINO-COSTA, J.; MALDONADO-TORRES, N.; GROSFOGUEL, R. (org.). Decolonialidade e pensamento afrodiaspórico. São Paulo: Autêntica, 2018. p. 139-170.

DEBIASI, R. E. Mulheres, militantes e migrantes: a estruturação do MST no Nordeste brasileiro. In: SEMINÁRIO INTERNACIONAL FAZENDO GÊNERO, 11. 2017, Florianópolis. Anais [...]. Florianópolis: Instituto de Estudos de Gênero, 2017. p. 1-11.

DEERE, C. D. Os direitos da mulher à terra e os movimentos sociais rurais na reforma agrária brasileira. Estudos Feministas, Florianópolis, v. 12, n. 1, p. 175-204, 2004.

DINERSTEIN, A. C. The politics of autonomy in Latin American: the art of organising hope. London: Palgrave MacMillan, 2015.

ESCOBAR, A. Territorios de diferencia: la ontología política de los “derechos al território”. Desenvolvimento e Meio Ambiente, Curitiba, v. 35, p. 89-100, 2015.

FEDERICI, S. Calibã e a bruxa: mulheres, corpos e acumulação primitiva. São Paulo: Elefante, 2017.

FREIRE, P. Pedagogia da esperança: um reencontro com a pedagogia do oprimido. São Paulo: Paz e Terra, 1992.

GONÇALVES, R. (Re)politizando o conceito de gênero: a participação política das mulheres no MST. Mediações, Londrina, v. 14, n. 2, p. 198-216, 2009.

LUGONES, M. Rumo a um feminismo descolonial. Estudos Feministas, Florianópolis, v. 22, n. 3, p. 935-952, 2014.

MARTINS, J. S. Os camponeses e a política no Brasil. 5. ed. Petrópolis: Vozes, 1995.

MESSENBERG, D. A cosmovisão da “nova” direita brasileira. In: PINHEIRO-MACHADO, R.; FREIXO, A. (org.). Brasil em transe: bolsonarismo, nova direita e 
desdemocratização. Rio de Janeiro: Oficina Raquel, 2019. p. 25-49.

MIES, M.; SHIVA, V. Ecofeminism. Melbourne: Spinifez, 1993.

MMC. Relatorias: $1^{\mathrm{a}}-12^{\mathrm{a}}$ assembleias estaduais MMC/SC. Passo Fundo: MMC, 1983-2014.

MST. Setor de Gênero. Caderno de formação. Porto Alegre: MST, 2017.

MULHERES, LGBTs e juventude do MST se juntam à mobilização "EleNão". MST, [s. l.], 28 set. 2018. Disponível em: https://mst.org.br/2018/09/28/mulheres-lgbts-ejuventude-do-mst-se-juntam-a-mobilizacao-elenao/ Acesso em: 7 jun. 2021.

PAREDES, J. Hilando fino: desde el feminismo comunitario. Ciudad de México: Ed. La Paz, 2013.

PAULILO, M. I. S. Mulheres rurais: quatro décadas de diálogo. Florianópolis: EdUFSC, 2016a.

. Que feminismo é esse que nasce na horta? Política \& Sociedade, Florianópolis, v. 15, p. 296-316, 2016b.

Trabalho familiar: uma categoria esquecida de análise. Estudos Feministas, Florianópolis, v. 12, n. 1, p. 229-252, 2004.

PINHEIRO-MACHADO, R. Amanhã vai ser maior: o que aconteceu com o Brasil e as possíveis rotas de fuga para a crise atual. São Paulo: Planeta do Brasil. 2019.
SANTOS, D. F.; ZIMMERMANN, S. A. O movimento de mulheres camponesas na construção do feminismo camponês popular. Norus, Pelotas, v. 7, n. 11, p. 269-299, 2019.

SANTOS, I. A. F.; PICOLOTTO, E. L. As mulheres do MST na luta pela terra e por fazer-se sujeitos políticos: rastros da experiência organizativa nas páginas do Jornal Sem Terra. Norus, Pelotas, v. 7, n. 11, p. 232-268, 2019.

SANTOS, I. A. F. "Sem mulher a luta vai pela metade": mulheres, feminismo e política no MST. 2019. Tese (Doutorado em Extensão Rural) - Universidade Federal de Santa Maria, Santa Maria, 2019.

STENGERS, I. Reativar o animismo. [S. l.]: Chão de Feira., 2017.

STROPASOLAS, V. L. O mundo rural no horizonte dos jovens. Florianópolis: EdUFSC, 2006.

TOLA, M. Composing with Gaia: Isabelle Stengers and the feminist politics of the Earth. PhaenEx, Windsor, v. 11, n. 1, p. 1-21, 2016.

WANDERLEY, M. N. B. Agricultura familiar e campesinato: rupturas e continuidade. Estudos Sociedade e Agricultura, Rio de Janeiro, v. 11, n. 2, p. 42-61, 2003. 


\section{RURAL SOCIAL MOVEMENTS AND FEMINISM: paths and dialogues in the construction of popular peasant feminism}

\author{
Iolanda Araújo Ferreira dos Santos \\ Janaina Betto
}

This article discusses political alternatives proposed by peasant women during rural social movements in Brazil, such as the Landless Workers Movement (MST) and the Peasant Women Movement (MMC). From bibliographic review, document analysis, interviews, and participation in events, we sought to understand how politically organized peasant women leaders have articulated alternatives to gender inequalities in rural areas and constructed feminism from their experiences in the country field. We perceive that their claims lead to a particular policy, created by women, but aimed for the overall society. From such policy emerges this feminism that, although under construction, already states the search for new gender, production, and nature relations, based on the daily practices of the peasant women. Despite the advance of neoconservatism in Brazil, these women have been building the popular peasant feminism as a movement of autonomy and hope.

Keywords: Peasant Feminism. Gender. Peasantry. Rural Women. Hope.

\section{DES MOUVEMENTS SOCIAUX RURAUX ET DES FÉMINISMES: parcours et dialogues dans la construction du féminisme paysan et populaire}

\author{
Iolanda Araújo Ferreira dos Santos \\ Janaina Betto
}

Cet article refléchit sur des alternatives politiques dont des femmes paysannes sont en train de construire le long des mouvements sociaux ruraux au Brésil(Mouvement des Travailleurs Ruraux SansTerre - MST et dans le Mouvement des Femmes Paysannes - MMC).De la revue bibliographique, de l'analyse des documents, de l'ouverture et de la participation à des événements, nous avons cherché à comprendre comment les femmes leaders paysannes politiquement organisées réfléchissent elles-mêmes aux alternatives aux inégalités dans les relations de genre en milieu rural et à la construction du féminisme depuis leurs expériences dans le pays champ. On comprend que leurs revendications ménent à une politique propre, édifié par des femmes pour toute la societé, d'où émerge ce féminisme encore en construction, mais que affirme déjà la recherche de: nouvelles rélations de genre, nouvelles rélations de production et avec la nature, depuis les pratiques quotidiennes du mode de vie des femmes paysannes. Même devant le progrès du néoconservatisme au Brésil, ces femmes sont en train de construire leféminismepaysan et populaireen tant quemouvement d'autonomie et espoir.

Motsclés: Féminisme Paysan. Genre. Paysannerie. Femmes Rurales. Espoir. em Extensão Rural da Universidade Federal de Santa Maria (PPGExR-UFSM). Vinculada ao Curso de Licenciatura em Educação do Campo da UFSM, como Tutora. Trabalha com as temáticas de mulheres camponesas, movimentos sociais rurais, lutas feministas e sociologia rural. Principal publicação: SANTOS, I.A.F.; PICOLOTTO, E.L. As mulheres do MST na luta pela terra e por fazer-se sujeitos políticos: rastros da experiência organizativa nas páginas do Jornal Sem Terra. Revista Novos Rumos Sociológicos, v. 7, n11, 2019.

Janaina Betto - Doutoranda no Programa de Pós-Graduação em Extensão Rural da Universidade Federal de Santa Maria (PPGExR-UFSM). Mestra em Extensão Rural (PPGExR-UFSM). Desenvolve pesquisas com os seguintes temas: mulheres camponesas, mulheres indígenas, movimentos sociais, política e cosmopolíticas. Principal publicação: BETTO, J.; PICCIN, M. B. Movimento de Mulheres Camponesas (MMC/SC) e o percurso de sua luta feminista. Amerika, Rennes, v. 16, 2017. 